\title{
Interpretation of the Reality in Environmental Education: Identification of Mono-, Multi-, Inter-, Trans-Disciplinary and Inter-Epistemic Experiences
}

\author{
Julio César Tovar-Gálvez ${ }^{1 *}$ [C
}

${ }^{1}$ Martin-Luther-Universität Halle-Wittenberg, GERMANY

*Corresponding Author: joule_tg@yahoo.com

Citation: Tovar-Gálvez, J. C. (2022). Interpretation of the Reality in Environmental Education: Identification of Mono-, Multi-, Inter-, TransDisciplinary and Inter-Epistemic Experiences. Interdisciplinary Journal of Environmental and Science Education, 18(3), e2274. https://doi.org/10.21601/ijese/11879

\section{ARTICLE INFO}

Received: 18 Jan. 2022

Accepted: 3 Mar. 2022

\begin{abstract}
The interpretation of reality is relevant to transforming environmental contexts. Environmental education (EE) might contribute to building more complex interpretations of reality. It seems that integrating disciplines is a way to reach complexity in interpreting reality. However, it is not easy for professionals and teachers to achieve such integration. Therefore, this paper aims to illustrate different interpretations of reality through specific educational reports on EE. This work is a qualitative and descriptive study of cases. The units to study are experiences in EE. The cases' selection depends on whether the document describes an experience or a practical proposal on developing EE. The analysis classifies the experiences as monodisciplinary, multidisciplinary, interdisciplinary, inter-epistemological or transdisciplinary. The results describe three cases per category. The discussion highlights that all the interpretations of reality are valuable and contribute, but a more complex framework probably will lead communities to broader and more profound interpretation and action.
\end{abstract}

Keywords: environmental education, monodisciplinary, multidisciplinary, interdisciplinary, interepistemological, transdisciplinary

\section{INTRODUCTION}

The interpretation of reality is relevant to transforming environmental contexts and environmental education (EE) might contribute to this purpose. The more complex humans interpret the reality; the greater possibility they will have to understand the environmental complexity. It seems that integrating disciplines is a way to reach complexity in interpreting reality. However, Lundershausen (2018) empirically demonstrated that scientific groups have limitations to achieving such integration. Moreover, Woiwode and Froese (2020) identify that the peer-review process for publishing favour monodisciplinary research. Therefore, education has a relevant role in changing this situation, educating citizens and professionals who have a complex interpretation of the environmental reality. Nonetheless, Riley and White (2019) warn about the EE that fragments the knowledge, the knower and the known. Therefore, this paper aims to illustrate different interpretations of reality through specific educational reports on EE.

An EE that considers developing the interpretation of the environmental reality might contribute to teachers' teaching practice and students' learning. First, when teachers have a guide about diverse interpretations of reality, they have a tool to enact policies about collaborative teaching and curriculum integration (Sund \& Gericke, 2020). Second, when teachers know how to integrate knowledge to reach different interpretations of reality, they have elements to guide students to collaborative learning, and knowledge, experiences, and feelings interchange (Nokkala et al., 2021). Likewise, teachers might lead students to negotiate better and make decisions regarding social-ecological issues (Sakamoto et al., 2021).

Integrating Epistemologies and Ontologies from Different Cultural Backgrounds

Addressing environmental phenomena from only one viewpoint or culture is a limitation to transforming the environmental reality. A way to overcome this limitation is the integration of epistemologies and ontologies belonging to the same culture and from different cultural backgrounds. Thus, communities would build new interpretations of reality, and hence, they will have more chances for transforming contexts or creating new environments. 
Some authors argue that the environmental problems and the EE limitations are mainstream Western culture. For instance, the problem for Williamson (2009) is the consumerist and scientific-technological Western system. For GarcíaCampos (2019), the limitation is the exclusively Westernbased sustainability vision. Moreover, according to Kapyrka and Dockstator (2012), EE curricula based solely on the Western culture have limitations. In all cases, the researchers propose to open the EE curriculum to include other visions of environment and sustainability and other communities more than the dominant culture. As an example, the authors recommend incorporating into the EE curriculum indigenous knowledge systems. This proposal is an example of epistemologies and ontologies integration.

There are advances in integrating epistemologies and ontologies in the science teacher education field. For instance, Tovar-Gálvez and Sedano (2014) propose to engage teachers in different levels of epistemic reflection to guide their practice. In the same focus, Tovar-Gálvez (2021a) presents the epistemological bridge (EB) as a frame to guide teachers to include in the classroom science and traditional epistemologies (from indigenous, afrodescendants, farmers, among others). Furthermore, Tovar-Gálvez and Acher (2021) develop two intercultural teaching practices for science education using the EB. Finally, Ludwig and El-Hani (2020) and Mpofu et al. (2014) recommend frames for teachers to identify and conduct the relationships among epistemologies and ontologies in the lessons.

The present study requires a framework on what "interpretation" is to identify and describe experiences in EE according to different ways of interpreting reality. Complex environmental formation theory (CEFT) offers insight into "reality interpretation" and guides faculty in integrating disciplines, epistemologies, and ontologies.

\section{Interpretation of Reality as the Self-Eco-Organisation of} Knowledge Systems

The interpretation of reality is the referent from which individuals understand the environment and guide their actions to a large degree. Individuals might have different interpretations of reality, leading to various responsibilities, possibilities, and commitments on environmental phenomena. When subjects integrate disciplines or knowledge systems, they have a framework to interpret the environmental reality more complexly. However, teachers, educators and researchers need this conception in the frame of an environmental educational theory. This need emerges because the interpretation of reality is more helpful to educational communities when its definition is regarding teaching and learning.

Puerto and Tovar-Gálvez (2020) propose the interpretation of reality as one of the six scenarios in which communities might identify the complexity in the EE processes. When communities evaluate the EE experiences, they might realise whether they reached a restricted, intermediate or self-ecoorganised interpretation of reality. Knowing this complexity level is a guide to transforming the EE processes for reaching a more complex thinking and action. The EE experiences improvement may consist of establishing new connections or integrations of knowledge systems to broaden the students' interpretation of reality.

The base of the scenarios and the classification levels is the CEFT (Tovar-Gálvez, 2020a, 2020b). The CEFT has ontological, epistemological, pedagogical, and didactic foundations in the self-eco-organisation of systems defined by Morin (1996). Self-organisation refers to the relations and connections between elements into a system. Eco-organisation relates to the links between systems.

Consequently, subjects self-organise knowledge when they learn and use the multiple dimensions of a knowledge system. For example, a vast literature about competences considers that students should learn the procedural (methodologies) and axiological (values system) dimensions of knowledge in addition to the theoretical one. When teachers promote students' learning in at least those three dimensions, they lead students to self-organise different dimensions of a knowledge system. Additionally, subjects eco-organise knowledge when they learn, connect and use diverse knowledge systems. Abundant literature suggests knowledge ecologies as the multi-, inter-, transdisciplinary, and inter-epistemic ones (knowledge systems from different ontologies). Teachers promote students' eco-organisation by integrating multiple knowledge systems (such as science, arts, humanities, social science, and indigenous knowledge).

\section{METHOD}

This work is a qualitative and descriptive study of cases. The units to study are experiences in EE. The papers' selection depends on whether the document describes an experience or a practical proposal on developing environmental education. The researcher used the Google Scholar browser to look for the papers. The search includes keywords combinations as "interdisciplinary + environmental education". The analysis classifies the experiences according to the different kinds of knowledge systems integration. Summarising and interpreting Klein (2020), Paoli (2019), and Renn (2021), it is possible to define the different types of knowledge systems integration and the characteristics of educational experiences, as follows:

1. Mono-disciplinary: Communities use one or multiple dimensions of a knowledge system to interpret, describe, analyse, explain, and/or solve an environmental problem. Teachers and students identify environmental situations and use the subject to study the situations. There is a connection between the contents and the context to address.

2. Multidisciplinary: Communities use different knowledge systems to interpret, describe, analyze, explain, and or solve an environmental problem. First, teachers in charge of varying subject matters identify a common environmental situation. Then, each teacher guides students to use the specific subject's theories, methods, and norms to address the problem. Activities to integrate results from the different subject matters are frequent.

3. Interdisciplinary: Communities integrate different knowledge systems to interpret, describe, analyze, 
explain, and/or solve an environmental problem. Teachers identify an environmental situation and propose activities that lead students to use the knowledge and methods from the different subject matters to address the situation. The interaction between the knowledge systems is necessary to study the problem. Co-teaching is a frequent activity.

4. Inter-epistemological: Communities use knowledge systems from different ontologies to interpret, describe, analyze, explain, and/or solve an environmental problem. Teachers identify an environmental situation and engage students in using different epistemologies to address it. Thus, teachers guide students in using knowledge, values and methodologies from the subject and from other cultural backgrounds to study the situation. Participation of people from communities culturally differentiated in the lessons is a usual activity.

5. Transdisciplinary: Communities use an integration of knowledge systems, communities, and institutions from different ontologies to interpret, describe, analyze, explain, and/or solve an environmental problem. Teachers identify environmental issues as complex and look for new frames to transform the environmental context. Teachers integrate disciplines from the official curriculum as interdisciplinary does, and they also include knowledge systems from other cultures as inter-epistemological does. Critical positions regarding the environmental contexts are a base for the transformation process. Likewise, the participation of communities and institutions beyond the education institution is necessary. However, the communities are not only beneficiaries or followers of the academic results regarding an environmental issue. Communities also are providers of knowledge and leaders in the transformation or solution.

\section{RESULTS}

The selection of the cases according to the analysis categories has limitations. First, some authors state that their reported experiences are transdisciplinary, but the experience is interdisciplinary or multidisciplinary after reading it. The same confusion happens with some apparently interdisciplinary experiences. Second, some experiences have essential elements to be classified into a category, but they do not always complete all the requirements.

\section{Cases from a Mono-Disciplinary Interpretation of the Environmental Reality}

Fragkoulis and Koutsoukos (2018) use artworks to motivate students to reflect on environmental issues. For example, the accumulation of waste in environments raises questions regarding consumerism, industry and market. The teachers and students analysed two artworks specifically, one constructed with natural material and another with recycled material. First, the teachers asked questions about the artworks to address "recycling and reuse of materials" and "the prudent management of natural resources". Then, the students looked for a new artwork with the same environmental sense.

Lorenzo et al. (2019) carry out an experience with preservice teachers to study the phenomenon of ocean acidification. The problem to address is that anthropogenic carbon dioxide emissions modify the acidity of the ocean. Researchers and pre-service teachers address the concept of $\mathrm{pH}$ using online resources and contextualised experimentation.

Porcel and Odetti (2020) guide pre-service teachers to propose environmental education projects from a sciencetechnology-society-environmental focus of chemistry. For the authors, engaging communities in using disciplinary knowledge to address contextual environmental problems ensures the sustainable development goals (SDGs). The preservice teachers proposed projects to solve community environmental issues into the frame of the SDG and from chemistry. The development of the projects engaged communities and governmental institutions.

\section{Cases from a Multidisciplinary Interpretation of the Environmental Reality}

Batista et al. (2019) report on a project by primary school teachers that links subject areas to an environmental issue. For the authors, the emergence of complex environmental problems demands a complex understanding and action. Thus, teachers in a school developed a multidisciplinary project addressing the environment's limit and the degradation caused by humans. In addition, every teacher proposed activities to engage students in using the disciplines to approach the problem.

Rogers et al. (2015) use sustainability-themed education modules to focus the subject-matter disciplines to an overarching environmental question. For the researchers, communities cannot address the current environmental issues as they did before. This complex perspective demands new pedagogies. Through the modules, the teachers engaged students in answering the general question. The students wrote technical reports summarizing and connecting their results in every subject.

Tovar-Gálvez (2021b) describes an example in which a school addresses the regional environmental problem of the city landfill. Some years ago, the dump exploded, throwing tons of rubbish, contaminating air, landscape, soil and the river alongside. Tovar-Gálvez (2021b) recommends that the school community interprets the context using a system of questions. Those questions aim to guide students and teachers to study the problem and think in social action from the different curriculum subject-matters.

\section{Cases from an Interdisciplinary Interpretation of the Environmental Reality}

Cachapuz (2020) explores the growing field of teaching science and art interdisciplinary. The author highlights that citizens with an interdisciplinary education have more diverse representations and experiences of reality. Moreover, he describes some research reports illustrating teaching integrating art and science. However, the core aspect for the author is that teachers address the knowledge, methodologies and logic from each discipline. 
Galvão et al. (2021) use four curricular units to connect disciplines to environmental problems. For the researchers, societal challenges are complex, so individuals need social and scientific knowledge for addressing them. The teachers presented two multidimensional contexts for the students to solve using what they learned in the units. The students built different proposals through inquiry. The students' proposals were viable and integrated knowledge from diverse areas.

Tan and So (2019) engage students in outdoor environmental education to connect diverse disciplines to address an overarching question. The authors consider that natural settings demand that students identify interactions. Consequently, students need to establish interactions between disciplines to read those natural interactions. Teachers of geography, history and biology engage students in an outdoor learning trail linked to pre-trial and post-trail phases (in class). The students could identify the connection between disciplines.

\section{Cases from an Inter-Epistemological Interpretation of the Environmental Reality}

Robles-Piñeros et al. (2020) engage students in identifying traditional ecological knowledge (TEK) and a unit relating TEK and biology to understand ecosystems and their sustainability. The authors point out that the development of the agriculture impacts the local ecosystems negatively and marginalise the TEK. Researchers, teachers and students visited crops to interview farmers to identify local TEK. Teachers develop a unit addressing ecological relations by studying elements from the context. Additionally, students used contextual cognition tables (Baptista, 2018) to reflect on the relationships between TEK and science.

Salamanca et al. (2015) worked on innovative activities to connect science and traditional community knowledge to reduce classroom waste. The authors find that despite the school environmental projects, the students do not identify the waste as a problem. For changing this situation, the teacher engaged students in a series of activities, including interviewing adults as parents, other relatives and key people in the waste management in the city. This dynamic was a possibility to connect science and community traditions.

Valderrama-Pérez et al. (2015) develop a unit addressing weather and climate from school science and fishers' knowledge. The addressed issue is that recent extreme variations of weather affect navigation, fishing, and welfare. Students and teachers approximate the phenomenon from two different epistemologies -the fishers' traditional knowledge on weather, climate and fishing cyclical variations and the description of intertropical and subtropical climate seasons provided by science.

\section{Cases from a Transdisciplinary Interpretation of the Environmental Reality}

Orozco-Messana et al. (2020) report on an international and multidisciplinary workshop to lead students from different countries to transdisciplinary skills. The researchers recognise that environmental problems are a challenge that disciplines cannot address in isolation. The workshop encompasses lectures, projects, social events and reflection. First, the social events are the way to develop a familiar environment between the participants. The teachers presented their perspectives from multiple disciplines to address the environmental issues. Moreover, the students worked on projects in small teams to propose multidimensional solutions.

Riley and Proctor (2021) establish a nexus between physical education and environmental education to guide students' learning theorising and living with/through the problem. The researchers problematized the urbanisation process in a forest near the school. First, the teachers and students discussed urbanisation and ecosystems' destruction, urbanisation increment, and health and well-being. Second, the class went on a ski ride to the park, took pictures and experienced the human/earth relationships.

Riley and White (2019) use "pedagogies attuning-with" to conduct outdoor education and environmental education. For example, during a bushwalking expedition, the teachers engaged students in a mindfulness activity to recognise themselves as part of the ecosystem. In another experience, the teachers involved the students in using knowledge from the social and natural sciences and emerging knowledge from interaction with people in a town to determine the river system's health.

\section{DISCUSSION}

All the interpretations of reality are valuable and contribute, but a more complex framework probably will lead communities to broader and more profound interpretation and action. For instance, it is valid and helpful that teachers guide students to understand the ocean contamination from chemistry. However, students would have more possibilities to understand and perhaps change the contamination issue when the teacher of social sciences leads them to understand the public policy on industry regulation. Another broader possibility for students is when teachers from chemistry, social science, informatics and physical education work in coteaching to guide students to address such an issue. The students would be able to understand the chemical reactions in the oceans, the policy limitations to control industrial waste discharges, the implications in public health and computer tools used to monitor changes in the ocean. Moreover, students could have a more profound framework to interpret the ocean contamination and its possible solution when teachers decide to integrate in the lessons indigenous communities. This indigenous paradigm might represent a new perspective to think and act regarding the environmental reality.

Taking into account the specific cases described in the results, it is possible to point on specific regularities, novelties and issues. For example, teachers focused the knowledge systems and their integrations on social-ecological problems in every case. Thus, teachers contributed to the citizen's and professional's construction of interpretations of reality. In addition, experiences that promoted more interaction between epistemologies, ontologies and communities offered students more possibilities to understand and intervene in reality.

There are frequent elements, sources, activities or practices when teachers focus knowledge systems on 
environmental realities. Commonly, teachers engage with students in

a. reflections on and critic of the consumerist culture,

b. problem or question-solving,

c. active pedagogies and work in the environmental contexts,

d. project-based learning, and

e. integrating and using the knowledge systems to solve a problem or answer questions.

In addition to the problem-question solving approach, the teachers used to address the SDGs and recycling as motivation for the projects or learning activities. Finally, the most complex strategies promote an interchange between the students and communities out of the school.

There are possible limitations for teachers to enact EE experiences with more complex interpretations of environmental realities. Some limitations have to do with the institutional dynamics, others with the teacher education in EE and others with the teachers' mastery of the methodologies. Regarding the institutions, the curriculum is rigid in many cases, and teachers have no chance to propose new contents, methodologies, or time administration. Moreover, institutional administrations do not support the teachers' proposals or innovations in some cases. Many times, concerning the teacher education programs, the EE is part only of the natural science teacher education (Briggs et al., 2018). Additionally, teachers do not always count on explicit environmental educational theories to guide, evaluate and research EE experiences (Puerto \& Tovar-Gálvez, 2020; Reddy, 2017).

Integrating knowledge systems to interpret the environmental reality is a possible content (concepts, methodologies, and practices) for teacher education programs. Introducing this frame would help solve the problem that Reddy (2017) identified regarding the difficulty of defining EE content for teacher education. Also, this content would solve the problem of explicitly including EE in teacher education programs (Franzen, 2017). For example, when the education faculties teach teachers about mono-, multi-, inter-, transdisciplinary and inter-epistemological didactics, they would offer elements for teaching in EE in addition to the discipline's contents. However, teaching to teach the construction of different interpretations of reality cannot be limited to the integrations' typology. It must be in a wider didactic frame, considering learning and its assessment. That is, the teachers, educators and researchers need those knowledge systems integration models expressed on teaching and learning key.

Perspectives for Guiding Teachers in the KnowledgeSystems Integration

The CEFT (Tovar-Gálvez, 2020a, 2020b) could guide teachers to enact different interpretations of reality in the lessons. The CEFT has ontological, epistemological, pedagogical and didactic foundations based on self-ecoorganisation. At the didactic level, the CEFT offers conceptual and methodological elements regarding learning, teaching, and assessment to teachers and communities. Regarding learning, the CEFT proposes the complex environmental competence (CEC), which encompasses some dimensions:

a. Cognitive: Knowledge systems (and all the integration possibilities) through which subjects approach reality,

b. Metacognitive: Subjects' ability to reflect on, manage and assess their learning,

c. Social: Collective learning and cooperative work,

d. Contextual: Subjects' action on their immediate environment,

e. Factual: The degree to which the subjects transform their environmental reality and

f. Identity: Personal, social, and professional commitments.

In teaching, the CEFT guides teachers to enact projects to self-eco-organise the community and the knowledge-thought. Projects consist of some parts:

a. Contextualisation: Subjects and communities recognise themselves (identities, territories, beliefs, values, knowledge) in the environmental context (their contribution to the environmental reality),

b. Situations definition: The communities delimit the part of the environmental reality they want to transform based on the contextualisation,

c. Environmental transformation program: The system of activities to transform the environmental reality,

d. Community education program: Activities to share what the community has learned and to engage other stakeholders,

e. Permanent evaluation program: The indicatorsactivities system that the community uses to determine if they are reaching the project's objectives (this is different to the teachers' assessment on the students' learning).

In assessment, the CEFT provides teachers with a set of scenarios to identify levels of complexity reached through the projects (Puerto \& Tovar-Gálvez, 2020). The six scenarios are, as follows:
a. Learning,
b. Teaching,
c. Curriculum,
d. Interpretation of reality,
e. Autonomy, and
f. Impact.

The assessment levels for the six scenarios are self-ecoorganised, intermediate and restricted. The indicators to assess the interpretation of reality are as the Table 1 describes.

\section{CONCLUSIONS}

The knowledge systems integration models are an opportunity to shape the students' and citizens' interpretation of reality. Interpretations of reality from a discipline can contribute to building a students' view of environmental issues. Nevertheless, when teachers guide students from a 
Table 1. Indicators for assessing interpretation of reality

Level Indicators. The interpretation of reality is characterised because...

It is self-organised because it integrates multiple dimensions of knowledge (conceptual, procedural, attitudinal, communicative,

Self-eco- $\quad$ and epistemic) within a specific discipline or vision to build the CEC.

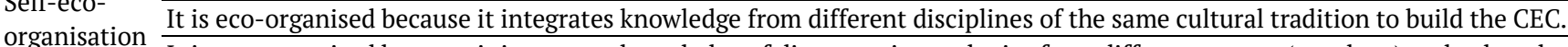

It is eco-organised because it integrates knowledge of diverse epistemologies from different nature (ontology) and cultural tradition to build the CEC.

It integrates all or some of the dimensions of knowledge within a discipline or vision to build the CEC.

Intermediate It privileges the knowledge of one of the various disciplines within the same cultural tradition to build the CEC. It privileges knowledge of one of various epistemologies from different nature (ontology) and cultural tradition to build the CEC. It integrates some dimensions of knowledge within a discipline or vision to build the CEC.

Restricted It does not integrate different disciplines within the same cultural tradition to build the CEC. It does not integrate various epistemologies from different nature (ontology) and cultural tradition to build the CEC.

Note. Source: (Puerto \& Tovar-Gálvez, 2020)

multi-, inter-, trans-disciplinary, or an inter-epistemic view, they have the opportunity of interpreting the environment more complexly. This complex interpretation of reality might guide the students' actions to transform environmental contexts.

It seems that addressing socio-ecological issues in the lessons leads teachers to enact non-traditional teaching practices. For example, the problem-question solving approach through projects is frequent, which is different from the traditional talking-teacher lessons. In addition, the most complex experiences link students to communities and institutions beyond the physical school, which differs from the four-wall traditional school. Teachers probably reached this complexity in teaching because they intended to address the environmental issues complexly. The diverse knowledge systems integration models supported those complex teaching practices.

The scarce institutional support and teacher education are limitations to using the knowledge systems integration models in the lessons. The educational public policy and institutional administration are a way to address the institutional obstacles. Instead, educational research has more opportunities to solve teacher education issues. In this last case, researchers might provide teachers and educators with knowledge systems integration frameworks.

However, there is literature that mastery explain what multidisciplinary, interdisciplinary and transdisciplinary is. However, those papers do not guide teachers on how to use those models in the classroom. For this reason, those knowledge systems integration models should be in the frame of an environmental education theory. The CEFT is a theory that frames the knowledge systems integration models in teaching and learning. The CEFT offers a conception and guidelines about teaching, learning and assessment based on the self-eco-organisation. Understanding the educational process from self-eco-organisation of systems is a way to integrate knowledge systems for shaping students' interpretation of reality and action.

Funding: No external funding is received for this article.

Declaration of interest: Author declares no competing interests.

Ethics approval and consent to participate: Not applicable.

Availability of data and materials: All data generated or analyzed during this study are available for sharing when appropriate request is directed to corresponding author.

\section{REFERENCES}

Baptista, G. C. S. (2018). Tables of contextual cognition: A proposal for intercultural research in science education. Cultural Studies of Science Education, 13(1), 845-863. https://doi.org/10.1007/s11422-017-9807-3

Batista, N. L., Feltrin, T., Cassol, M. S., Busnello, M., Ziembowicz, F. I., de Vargas, L. F., \& Pigatto, M. M. (2019). A multidisciplinary proposal for environmental education with 6th years of fundamental education in Santa Maria/RS. Vivências [Experiences], 15(28), 193-205. https://doi.org/10.31512/vivencias.v15i28.28

Briggs, L., Trautmann, N., \& Fournier, C. (2018). Environmental education in Latin American and the Caribbean: The challenges and limitations of conducting a systematic review of evaluation and research. Environmental Education Research, 24(12), 1631-1654. https://doi.org/10.1080/13504622.2018.1499015

Cachapuz, A. (2020). Arte e ciência no ensino interdisciplinar das ciências [Art and science in interdisciplinary science teaching]. Revista Internacional de Pesquisa em Didática das Ciências e Matemática [International Journal of Research in Didactics of Science and Mathematics], 1, e020009. https://periodicoscientificos.itp.ifsp.edu.br/index.php/rev in/article/view/89

Fragkoulis, I., \& Koutsoukos, M. (2018). Environmental education through art: A creative teaching approach. Education Quarterly Reviews, 1(2), 83-88. https://doi.org/10.31014/aior.1993.01.01.8

Franzen, R. L. (2017). Environmental education in teacher education programs: Incorporation and use of professional guidelines. Journal of Sustainability Education, 16. http:// susted.com/RATS_2.3/UploadsFinalPDFs/459_2018-0108\%2017.17.39_Franzen\%20JSE\%20Fall\%202017\%20Gene ral\%20PDF.pdf

Galvão, C., Faria, C., Viegas, W., Branco, A., \& Goulão, L. (2021). Inquiry in higher education for sustainable development: Crossing disciplinary knowledge boundaries. International Journal of Sustainability in Higher Education, 22(2), 291-307. https://doi.org/10.1108/IJSHE-02-20200068 
García-Campos, H. (2019). Environmental education from an intercultural approach: A glimpse into Latin America. Southern African Journal of Environmental Education, 35, 111. https://doi.org/10.4314/sajee.v35i1.12

Kapyrka, J., \& Dockstator, M. (2012). Indigenous knowledges and western knowledges in environmental education: Acknowledging the tensions for the benefits of a "twoworlds" approach. Canadian Journal of Environmental Education, 17, 97-112. https://cjee.lakeheadu.ca/article/ view/1069

Klein, J. T. (2020). Sustainability and collaboration: Crossdisciplinary and cross-sector horizons. Sustainability, 12(4), 1515. https://doi.org/10.3390/su12041515

Lorenzo, M., Álvarez, M., Arias, A., \& Pérez, U. (2019). Aprender a interpretar la acidificación oceánica con recursos on-line y experimentación contextualizada [Learn to interpret ocean acidification with online resources and contextualized experimentation]. Enseñanza de las Ciencias [Science Education], 37(2), 189-209. https://doi.org/ 10.5565/rev/ensciencias.2564

Ludwig, D., \& El-Hani, C. N. (2020). Philosophy of ethnobiology: Understanding knowledge integration and its limitations. Journal of Ethnobiology 40(1), 3-20. https://doi.org/10.2993/0278-0771-40.1.3

Lundershausen, J. (2018). The anthropocene working group and its (inter-)disciplinarity. Sustainability: Science, Practice and Policy, 14(1), 31-45. https://doi.org/10.1080/ 15487733.2018.1541682

Morin, E. (1996). Thought ecologized. Gazeta de Antropología [Gazette of Anthropology], 12, 1-7. www.ugr.es/ pwlac/ G12_01Edgar_Morin.pdf

Mpofu, V., Otulaja, F., \& Mushayikwa, E. (2014). Towards culturally relevant classroom science: A theoretical framework focusing on traditional plant healing. Cultural Studies of Science Education, 9, 221-242. https://doi.org/ 10.1007/s11422-013-9508-5

Nokkala, T., Aarnikoivu, M., \& Kiili, J. (2021). Multidisciplinary peer-mentoring groups supporting knowledge sharing in doctoral education. Scandinavian Journal of Educational Research. https://doi.org/10.1080/00313831.2021.1939142

Orozco-Messana, J., de la Poza-Plaza, E., \& Calabuig-Moreno, R. (2020). Experiences in transdisciplinary education for the sustainable development of the built environment, the ISAlab workshop. Sustainability, 12(3), 1143. https://doi.org/10.3390/su12031143

Paoli, F. (2019). Multi- inter-, and transdisciplinarity. Problema. Anuario de filosofía y teoría del derecho [Problem. yearbook of philosophy and theory of law], 13, 347-357. http://www.scielo.org.mx/pdf/paftd/n13/2007-4387paftd-13-347.pdf

Porcel, M., \& Odetti, H. (2020). School environmental projects as a local awareness factor: A case study in a rural high school. Indagatio Didactica [Inquiry into Teaching], 12(4), 41-55. https://doi.org/10.34624/id.v12i4.21652
Puerto Layton, C. M., \& Tovar-Gálvez, J. C. (2020). Proposal for an assessment system of environmental education processes based on complexity expressions scenarios. Revista Internacional de Formação de Professores, 5, e020029. https://periodicoscientificos.itp.ifsp.edu.br/ index.php/rifp/article/view/236

Reddy, C. (2017). Environmental education in teacher education: A viewpoint exploring options in South Africa. Southern African Journal of Environmental Education, 33, 117-126. https://doi.org/10.4314/sajee.v.33i1.9

Renn, O. (2021). Transdisciplinarity: Synthesis towards a modular approach. Futures, 130, 102744. https://doi.org/ 10.1016/j.futures.2021.102744

Riley, K., \& Proctor, L. (2021). A physical education/environmental education nexus: Transdisciplinary approaches to curriculum for a sense of belonging. Australian Journal of Environmental Education, 1-12. https://doi.org/10.1017/aee.2021.29

Riley, K., \& White, P. (2019). 'Attuning-with', affect, and assemblages of relations in a transdisciplinary environmental education. Australian Journal of Environmental Education, 35, 262-272. https://doi.org/ 10.1017/aee.2019.30

Robles-Piñeros, J. Ludwig, D. Baptista, G. C. S., \& MolinaAndrade, A. (2020). Intercultural science education as a trading zone between traditional and academic knowledge. Studies in History and Philosophy of Biological and Biomedical Sciences, 84, 101337. https://doi.org/10.1016/ j.shpsc.2020.101337.

Rogers, M., Pfaff, T., Hamilton, J., \& Erkan, A. (2015). Using sustainability themes and multidisciplinary approaches to enhance STEM education. International Journal of Sustainability in Higher Education, 16(4), 523-536. https://doi.org/10.1108/IJSHE-02-2013-0018

Sakamoto, M., Yamaguchi, E., Yamamoto, T., \& Wakabayashi, K. (2021). An intervention study on students' decisionmaking towards consensus building on socio-scientific issues. International Journal of Science Education, 43(12), 1965-1983. https://doi.org/10.1080/09500693.2021. 1947541

Salamanca, A., Molina Andrade, A., \& Melo, N. (2015). The classroom basket: When the waste is not already trash. In $X$ Encontro Nacional de Pesquisa em Educação em Ciências [X National Meeting of Research in Science Education]. ABRAPEC. http://www.abrapecnet.org.br/enpec/x-enpec/ anais2015/resumos/R1632-1.PDF

Sund, P., \& Gericke, N. (2020). Teaching contributions from secondary school subject areas to education for sustainable development-A comparative study of science, social science and language teachers. Environmental Education Research, 26(6), 772-794. https://doi.org/10.1080/ 13504622.2020.1754341

Tan, E., \& So, H.-J. (2019). Role of environmental interaction in interdisciplinary thinking: From knowledge resources perspectives. The Journal of Environmental Education, 50(2), 113-130. https://doi.org/10.1080/00958964.2018.1531280 
Tovar-Gálvez, J. C. (2020a). Currículo de educación ambiental desde la complejidad: construcción de la competencia ambiental a través de proyectos [Environmental education curriculum from complexity: construction of environmental competence through projects]. In A. Hernández, Rç Ramírez, \& O. Escobar (Eds). Educación ambiental en el siglo XXI: del trayecto de construcción a la imperiosa necesidad [Environmental education in the 21st century: from the construction journey to the urgent need] (pp. 105-140). CIAD-CONACYT. https://bit.ly/3E1NwAn

Tovar-Gálvez, J. C. (2020b). Reducing the gap between theory and practice during the pandemic: Planning a complex virtual environmental project. Revista Internacional De Pesquisa Em Didática Das Ciências E Matemática, 1, e020017. https://bit.ly/38MLYeR

Tovar-Gálvez, J. C. (2021a). The epistemological bridge as a framework to guide teachers to design culturally inclusive practices. International Journal of Science Education, 43(5), 760-776. https://doi.org/10.1080/09500693.2021.1883203

Tovar-Gálvez, J. C. (2021b). Bringing environmental education to the curriculum: Practical elements emergent from teaching experiences and research. Interdisciplinary Journal of Environmental and Science Education, 17(3), e2236. https://doi.org/10.21601/ijese/9606

Tovar-Gálvez, J. C., \& Acher, A. (2021). Design of intercultural teaching practices for science education based on evidence. Enseñanza de las Ciencias, 39(1), 99-115. https://doi.org/10.5565/rev/ensciencias. 2891
Tovar-Gálvez, J. C., \& Sedano Aguilar, W. (2014). Taller: Niveles de reflexión epistémica en didáctica de las ciencias [Workshop: Levels of epistemic reflection in science education]. In Memorias del III Congreso Internacional y $\mathrm{V}$ Nacional de Educación Pedagogía y Cultura Ambiental [Proceedings of the III International and V National Congress of Education, Pedagogy and Environmental Culture] (pp. 499-504). Universidad de la Amazonía. https://doi.org/10.13140/2.1.1662.1128

Valderrama-Pérez, D., Molina, A., \& El-Hani, C. N. (2015). Dialogue between scientific and traditional knowledge in the science classroom: Development study of a teaching sequence in a school in Taganga (Magdalena, Colombia). Procedia-Social and Behavioral Sciences, 167, 217-222. https://doi.org/10.1016/j.sbspro.2014.12.665

Williamson Castro, G. J. M. (2009). Educación ambiental intercultural: ¿un nuevo paradigma? [Intercultural environmental education: A new paradigm?] Revista Colombiana de Educación [Colombian Journal of Education], 56, 132-155. https://doi.org/10.17227/01203916.7583

Woiwode, H., \& Froese, A. (2020). Two hearts beating in a research centers' chest: How scholars in interdisciplinary research settings cope with monodisciplinary deep structures, Studies in Higher Education, 46(11), 2230-2244. https://doi.org/10.1080/03075079.2020.1716321 